\title{
Fiabilidad sociopolítica en caficultores de Huitzilac, Morelos (centro de México) ${ }^{1}$
}

\author{
García Lirios, Cruz²; Carreón Guillén, Javier ${ }^{3}$; Hernández Valdés, Jorge ${ }^{4}$; Bustos Aguayo
} José, Marcos. ${ }^{5}$

Recibido: 6 de marzo de 2017 / Aceptado: 9 de mayo de 2017

Resumen. La fiabilidad entre ciudadanos y gobernantes ha sido estudiada desde la gestión y administración, la autogestión y la incidencia, la cogestión y la coadministración. Sin embargo, el emprendimiento y la innovación parecen ser independientes a la fiabilidad. El objetivo del estudio fue establecer la confiabilidad y la validez de un instrumento que mide la fiabilidad. Se llevó a cabo un estudio no experimental con una selección no probabilística de 340 caficultores en una localidad del centro de México. La fiabilidad de gestión explicó el mayor porcentaje de varianza total, pero se advierten sus límites.

Palabras clave: Gobernanza; caficultura; fiabilidad; emprendimiento; desarrollo local.

\section{[en] Sociopolitical reliability in coffee growers in Huitzilac, Morelos (central Mexico)}

\begin{abstract}
The reliability between citizens and rulers has been studied from management and administration, self-management and advocacy, co-management and co-administration. However, entrepreneurship and innovation seem to be independent of reliability. The aim of the study was to establish the reliability and validity of an instrument that measures reliability. A non-experimental study was carried out with a non-probabilistic selection of 340 coffee growers in a locality of central Mexico. Management reliability explained the highest percentage of total variance, but its limits were noted.
\end{abstract}

Keywords: Governance; coffee-growing; reliability; entrepreneurshi; local development.

Sumario. 1. Ámbitos caficultores globales. 2. Método. 3. Resultados. 4. Conclusión. 5. Discusión. 6. Referencias bibliográficas.

\footnotetext{
1 Artículo financiado por la Universidad Nacional Autónoma de México, Dirección General de Asuntos del Personal Académico, Programa de Apoyo a Proyectos de Investigación e Innovación Tecnológica, número IN305516

${ }^{2}$ Universidad Nacional Autónoma de México (México) cgarcia213@uaemex.mex

${ }^{3}$ Universidad Nacional Autónoma de México (México) javierg@unam.mx.

${ }^{4}$ Universidad Nacional Autónoma de México (México)

jorheval@unam.mx

${ }^{5}$ Universidad Nacional Autónoma de México (México) marcos.bustos@unam.mx
} 
Cómo citar: García Lirios, Cruz et al. (2017). "Fiabilidad sociopolítica en caficultores de Huitzilac, Morelos (centro de México)", en Mediaciones Sociales, 16, 231-244.

\section{1. Ámbitos caficultores globales y locales}

La Organización para la Cooperación y el Desarrollo Económico (OCDE) y la Organización de las Naciones Unidas para la Alimentación y la Agricultura (FAOO) en su informe correspondiente a 2015 advierte que la economía del café está determinada por su producción en micro escenarios (menos de una hectárea) que produce el $17 \%$ del total mundial, pequeños escenarios (de 1,1 a 5 hectáreas) que generan el 53\% del total de la producción mundial, seguidos de los medianos escenarios $(5,1$ a 20 hectáreas) que producen el $19 \%$ del total mundial y los grandes escenarios (más de 20 hectáreas) que general sólo el 11\% del total mundial (OCDE-FAO, 2015).

La OCDE-FAO (2015)) señala que Brasil lidera la lista de países exportadores con el 35,3\% (50,8 millones de sacos) del total mundial, seguido de Vietnam con 15,2\% (22 millones de sacos), Indonesía con el 8,70\% (20,2 millones de sacos), Colombia con el 6,5\% (9,5 millones de sacos) y Etiopía con 5,6\% (8,1 millones de sacos).

La producción del café, al igual que los productos orgánicos, depende de la estabilidad de la temperatura y el ciclo pluvial, pero en el caso de México, ambas cuestiones han variado significativamente repercutiendo en la planificación estatal al micro-financiamiento de pequeños caficultores (Guillén, 2010).

Los productores de café, en aquellas zonas con una alta variación de la temperatura y una significativa pérdida de precipitaciones, han tenido que establecer alianzas estratégicas con otros caficultores que, con el auspicio del gobierno federal y local han generado una dinámica de recolección de septiembre a marzo en doce estados de la república del centro y sur del país.

No obstante que las variaciones de la temperatura y las variaciones de las precipitaciones pluviales contrarrestan la producción del café en México, Chiapas alcanzó un margen alto de productividad con 500 mil toneladas por hectárea, seguido de Veracruz con 450 mil toneladas por hectáreas y Puebla con $400 \mathrm{mil}$ toneladas por hectárea.

Sin embargo, en aquellas zonas productoras de café que no están consideradas como parte del corredor caficultor están exentos de apoyo gubernamental en cuanto al financiamiento, asesoramiento y transferencia de tecnología y comercialización. Es el caso de Huitzilac, municipio del Estado de Morelos en el centro de México.

En un escenario desfavorable, las relaciones de empatía, confianza, compromiso y solidaridad entre caficultores y autoridades son fundamentales para activar el desarrollo local sustentable (Carreón et al., 2017). Se trata de la fiabilidad sociopolítica que consiste en el establecimiento de alianzas estratégicas entre gobernantes y gobernados con la finalidad de promover una actividad económica y prevenir crisis ambientales, económicas, políticas y sociales como inundaciones, sequías, desempleo, corrupción y delincuencia.

Tres teorías explican el proceso de fiabilidad sociopolítica: la teoría del capital social, la teoría del desarrollo humano y la teoría de la gobernanza corresponsable. 
Desde la teoría del capital social, la fiabilidad sociopolítica refiere a una relación solidaria y cooperativa; en la teoría del desarrollo humano la fiabilidad se considera identidad de formación colectiva y en la teoría de la gobernanza corresponsable la fiabilidad alude a la legitimación de un poder compartido, bidireccional y horizontal (Innerarty, 2012).

En el caso de una comunidad productora de café, la fiabilidad sociopolítica es un indicador de capital social, desarrollo humano y gobernanza corresponsable en el momento en que las autoridades incentivan o fomentan a las micros, pequeñas y medianas empresas, las cuales generan el 90\% de los empleos locales (García et al., 2016).

De este modo, la fiabilidad sociopolítica es un factor psicológico que artículo dimensiones ambientales, económicas, políticas y sociales. En el caso de la caficultura, producción y comercialización del café, la fiabilidad sociopolítica es fundamental para explicar los conflictos y los cambios locales.

La teoría del capital social advierte que un conflicto entre gobernantes y gobernados no sólo es generado por una ausencia de fiabilidad sociopolítica sino, además es propiciado por la emergencia de un posible cambio ante el cual los actores se resisten o transfieren sus intereses particulares al colectivo, afectando la solidaridad y la cooperación (Sandoval et al., 2017).

La teoría del desarrollo humano señala que un conflicto es un área de oportunidad que implicará a los actores en la búsqueda de soluciones para las cuales se genera una identidad común. Si la producción y comercialización de café son asumidas como un bien y un futuro común, entonces los actores políticos y sociales orientarán sus capacidades hacia la obtención de una identidad que las distinga de otras comunidades.

La teoría de la gobernanza corresponsable sugiere que el conflicto antecede a un consenso y éste a un cambio. Se trata de un proceso en el que la fiabilidad orienta las diferencias, establece acuerdos y propicia nuevos escenarios (Araujo, 2012).

En cada uno de los tres marcos teóricos, la fiabilidad sociopolítica explica una parte del proceso, según el cual las diferencias entre gobernantes y gobernados, propiciadas por crisis ambientales, económicas, políticas o sociales, pueden ser dirimidas en consensos, cogestiones y coadministraciones.

Incluso, la teoría del capital social entiende que el desarrollo humano es una consecuencia de la fiabilidad solidaria y cooperativa, así como éste desarrollo humano antecede a la gobernanza corresponsable en la que ambos son sistemas de fiabilidad materializados en una identidad negociadora, mediadora y conciliadora.

Del mismo modo, la teoría del desarrollo humano supone que el capital social es una forma de fiabilidad identitaria que se expresa en la colaboración y la solidaridad, pero que se traduce en una negociación frente a actores políticos y sociales conscientes de su interdependencia.

Es el mismo caso de la teoría de la gobernanza corresponsable al visualizar a la cooperación y la solidaridad como antecedentes de consensos, no sólo porque los acuerdos sean más factibles entre quienes se apoyan sino, porque una identidad colectiva indica un alto grado de cogestión entre dirigentes y seguidores.

Sin embargo, existen diferentes grados de confianza que el presente estudio se propuso dilucidar mediante la confiabilidad y la validez de una escala que mide cuatro dimensiones de la fiabilidad política (Piña, 2012). 
La fiabilidad, definida como un grado de confianza entre ciudadanía para con sus gobernantes en contextos de bonanza, desaceleración, recesión o crisis económica, está indicada por las solicitudes y el monto de micro-financiamiento a empresas con menos de 30 empleados (Santamaría, 2012).

No obstante, en situaciones de riesgo y contingencias, la fiabilidad social no es posible medirla a partir de las solicitudes y el micro-financiamiento. Más bien, la fiabilidad en contextos de crisis política o económica, se mide desde el grado de confianza en las oportunidades y las capacidades de los actores (Rodríguez, 2010).

De este modo, la fiabilidad social se origina ante una crisis de gobernabilidad en la que la propaganda de la rectoría del Estado es reducida con una contrapropaganda que consiste en deslegitimar la autoridad del Estado y enaltecer la organización y acción colectiva (Nin, 2012). Un buen indicador de la fiabilidad social es la participación en sus dimensiones heterogéneas (Pérez, 2010).

En ese sentido, cuando el clima de incertidumbre deriva de las políticas de micro-financiamiento, entonces la fiabilidad adquiere un sentido político y se observa en el grado de confianza hacia las autoridades por sus capacidades de gestión y administración de las demandas sociales y los recursos disponibles (Innerarity, 2012).

Por último, cuando la legitimidad del Estado y la participación civil es cuestionada, entonces la fiabilidad alude al grado de gobernanza que ambos actores políticos y sociales son capaces de llevar a cabo con la finalidad de emprender un futuro común con base en una corresponsabilidad (Maisley, 2013).

Algunos estudios muestran que la fiabilidad depende de las emociones que la ciudadanía tiene con respecto a la capacidad del estado para garantizar la seguridad pública. Carreón et al., (2014) demostró que la fiabilidad está indicada por la confianza, pero también por emociones de zozobra, indignación, miedo y enojo (Carreón et al., 2014). Es decir, la fiabilidad parece tener un sentido político ya que, la rectoría del Estado, instrumentada por sus programas y estrategias, genera emociones que se asocian a la confianza de las instituciones encargadas de prevenir el delito o impartir justicia (Guillén, 2010).

En se tenor de la desconfianza y las emociones, Carreón y García (2014) demostraron la amplificación social de la fiabilidad cuando el Estado procura el delito, fomenta el emprendimiento y protege a la sociedad civil ante desastres y catástrofes ambientales (Carreón y García, 2014), pero cuando la ciudadanía asocia la corrupción a la violencia, el desempleo y a las contingencias ambientales, entonces no sólo la fiabilidad se reduce a su mínima expresión, sino además genera una anti-propaganda que consiste en la supresión de la autoridad y el acoso a servidores públicos a través de los medios de comunicación (Escobar, 2012).

Es decir que la fiabilidad tendría dimensiones emotivas, pero también cognitivas. El estudio de García et al., (2015a) demostró que las dimensiones emotivas de zozobra, indignación, miedo y enojo tienen bajas correlaciones con las dimensiones cognitivas de percepción de riesgo, actitud hacia la autoridad e intenciones de voto (García et al, 2015). Ambas dimensiones, afectiva y cognitiva parecen conformar una estructura de desconfianza y confianza hacia las autoridades, pero sobre todo hacia su gestión y administración (Díaz, 2013).

García et al., (2015b) encontraron diferencias significativas entre quienes recibían micro-financiamientos con respecto a quienes no recibían el apoyo 
financiero en dos ámbitos locales parecidos. La amplificación social de la fiabilidad ocurrió cuando ambos grupos asociaron el otorgamiento de los recursos con la inseguridad local (García et al, 2015).

Sin embargo, los estudios no han identificado las dimensiones alusivas a la cogestión y la coadministración entre actores políticos y civiles con respecto a los recursos y los servicios públicos.

De este modo, la fiabilidad relativa a la gestión y coadministración supone un continuo de desconfianza o bajo grado de confianza hasta un mínimo grado de desconfianza o alto grado de confianza con respecto a una evaluación civil que a menudo se cristaliza en opiniones acerca de la disminución o aumento de alguna problemática local y las capacidades de respuesta ante tal situación.

En el caso de la cogestión y la coadministración, la fiabilidad más bien refiere a las capacidades de negociación, mediación, conciliación, arbitraje y enjuiciamiento de los actores políticos con respecto a las demandas, necesidades y expectativas sociales.

- Planteamiento: ¿En una localidad dedicada a la caficultura, las dimensiones de fiabilidad -gestión, administración, cogestión y coadministración- revisadas en la literatura, se ajustarán a los datos observados y ponderados en el estudio empírico?

- Hipótesis nula: En una localidad dedicada a la caficultura, las dimensiones de fiabilidad alusivas a la gestión, administración, cogestión y coadministración revisadas en la literatura se ajustarán a las dimensiones observadas y ponderadas en el estudio empírico.

- Hipótesis alterna: En una localidad dedicada a la caficultura, las dimensiones de fiabilidad relativas a la gestión, administración, cogestión y coadministración revisadas en la literatura son diferentes a las dimensiones empíricas encontradas y ponderadas en el estudio.

- Escenario. El municipio caficultor al colindar con la ciudad de Valles y por su cercanía con la Huazteca, recibe una cantidad significativa de turísticas y consumidores de café orgánico ya que, es zona de paso de una u otra zona.

El clima predominante del estado de San Luis Potosí es cálido subhúmedo con lluvias en verano, pero el clima del municipio caficultor es dual: semifrío húmedo con abundantes lluvias en verano y semifrío subhúmedo con lluvias en verano (INEGI, 2015).

Respecto a su preferencia electoral, el estado de San Luis Potosí es gobernado por un partido con una ideología de izquierda -garantía respeto a las decisiones minoritarias, autonomía relativa de las instituciones-, pero el municipio de caficultor es administrado por un partido de ideología de derecha -liberal en cuestiones económicas, pero conservador en cuestiones privadas- obtuvo la mayoría de los votos en las elecciones locales de 2015 y actualmente lidera la intención de voto para los comicios de 2018.

El municipio caficultor es un escenario de emergencia económica por un clima favorable al turismo y la comercialización del café, pero con una diferencia ideológica en sus gobiernos estatal y municipal. 


\section{Método}

- Diseño. Estudio no experimental, transversal y exploratorio.

- Participantes. Selección no probabilística de 340 caficultores y comerciantes.

- Instrumento. Se utilizó la Escala de Fiabilidad Sociopolítica de Carreón (2016) la cual incluye 28 ítems en torno a la confianza de la sociedad civil hacia sus gobernantes en materia de gestión y administración, cogestión y corresponsabilidad en torno a la caficultura. Cada ítem incluye opciones de respuesta que van desde $0=$ nada probable, $1=$ muy poco probable, $2=$ poco probable, 3 = probable, 4 = muy probable (Carreón, 2016).

- Procedimiento. Se utilizó la técnica Delphi para la homogenización de los conceptos incluidos en los reactivos de la escala. Se informó a los encuestados acerca del objetivo del estudio y se garantizó su confidencialidad por escrito. Las encuestas se aplicaron en la oficina de micro-financiamiento de la localidad y fue procesada con el Paquete Estadístico para Ciencias Sociales (SPSS por su acrónimo en inglés versión 18,0). Se estableció la confiabilidad con el parámetro alfa de Cronbach, la validez con un análisis factorial exploratorio de ejes principales con rotación promax, el ajuste con los parámetros de bondad de ajuste y residual.

\section{Resultados}

La tabla 1 muestra las alfas de Cronbach que miden la consistencia interna de la Escala de Fiabilidad (alfa de 0,891) y las subescalas de fiabilidad gestora (alfa de 0,890), fiabilidad administrativa (alfa de 0,893), fiabilidad cogestora (alfa de 0,895 ) y fiabilidad coadministrativa (alfa de 0,897 ).

Tabla 1. Normalidad, confiabilidad y validez del instrumento

\begin{tabular}{|c|c|c|c|c|c|c|c|c|}
\hline Código & Subescala / Ítem & $M$ & $\overline{D E}$ & Alfa & $F 1$ & $F 2$ & F3 & F4 \\
\hline & $\begin{array}{l}\text { Subscala de } \\
\text { fiabilidad gestora }\end{array}$ & & & 0,890 & & & & \\
\hline FG1 & $\begin{array}{l}\text { El gobierno } \\
\text { conseguirá los } \\
\text { micro- } \\
\text { financiamientos } \\
\text { para caficultores }\end{array}$ & 3,01 & 1,02 & 0,801 & 0,302 & & & \\
\hline FG2 & $\begin{array}{l}\text { Las ferias del café } \\
\text { serán prioridad } \\
\text { para el gobierno }\end{array}$ & 3,25 & 1,04 & 0,832 & 0,327 & & & \\
\hline FG3 & $\begin{array}{l}\text { El gobierno } \\
\text { promoverá la }\end{array}$ & 3,45 & 1,25 & 0,834 & 0,382 & & & \\
\hline
\end{tabular}




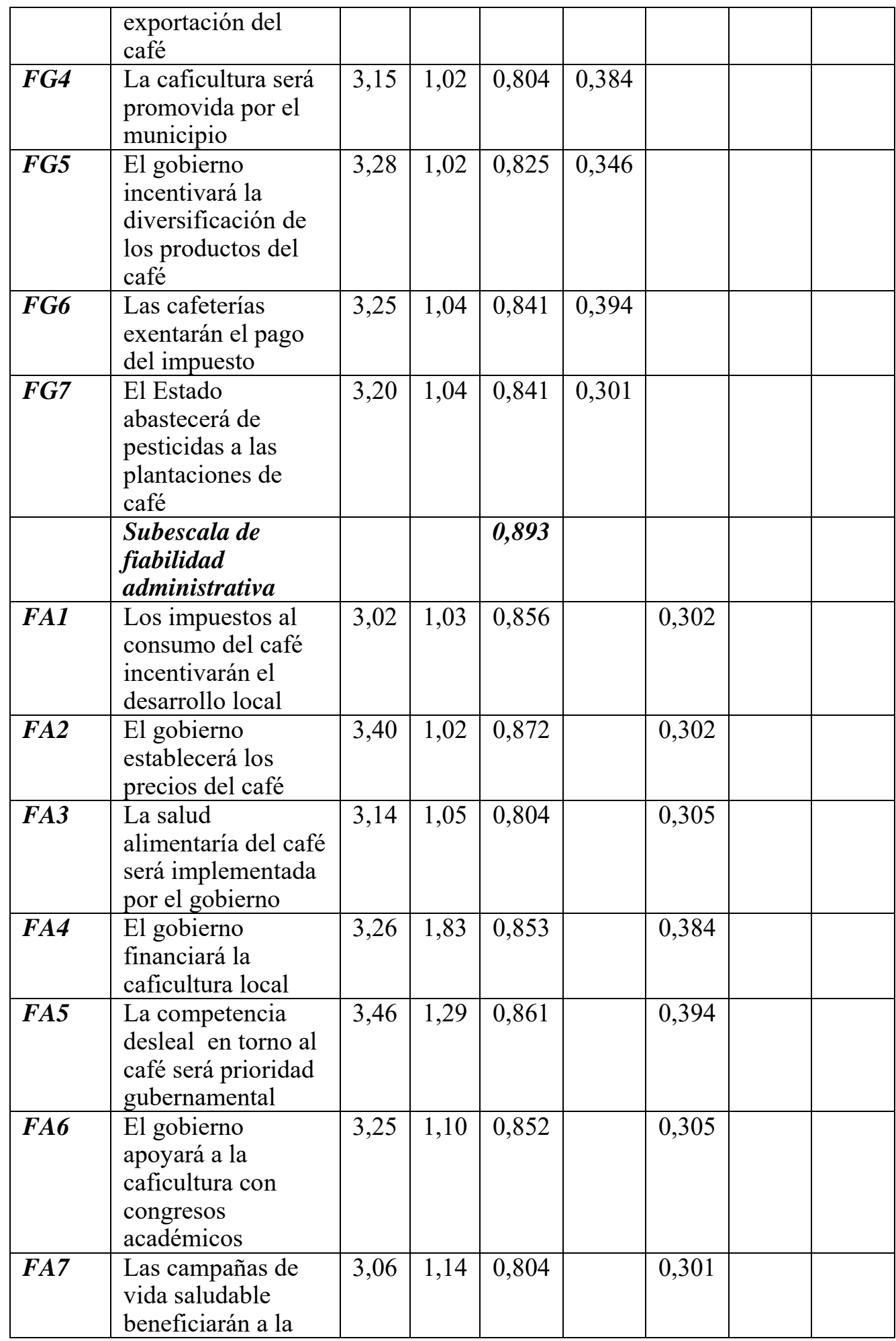




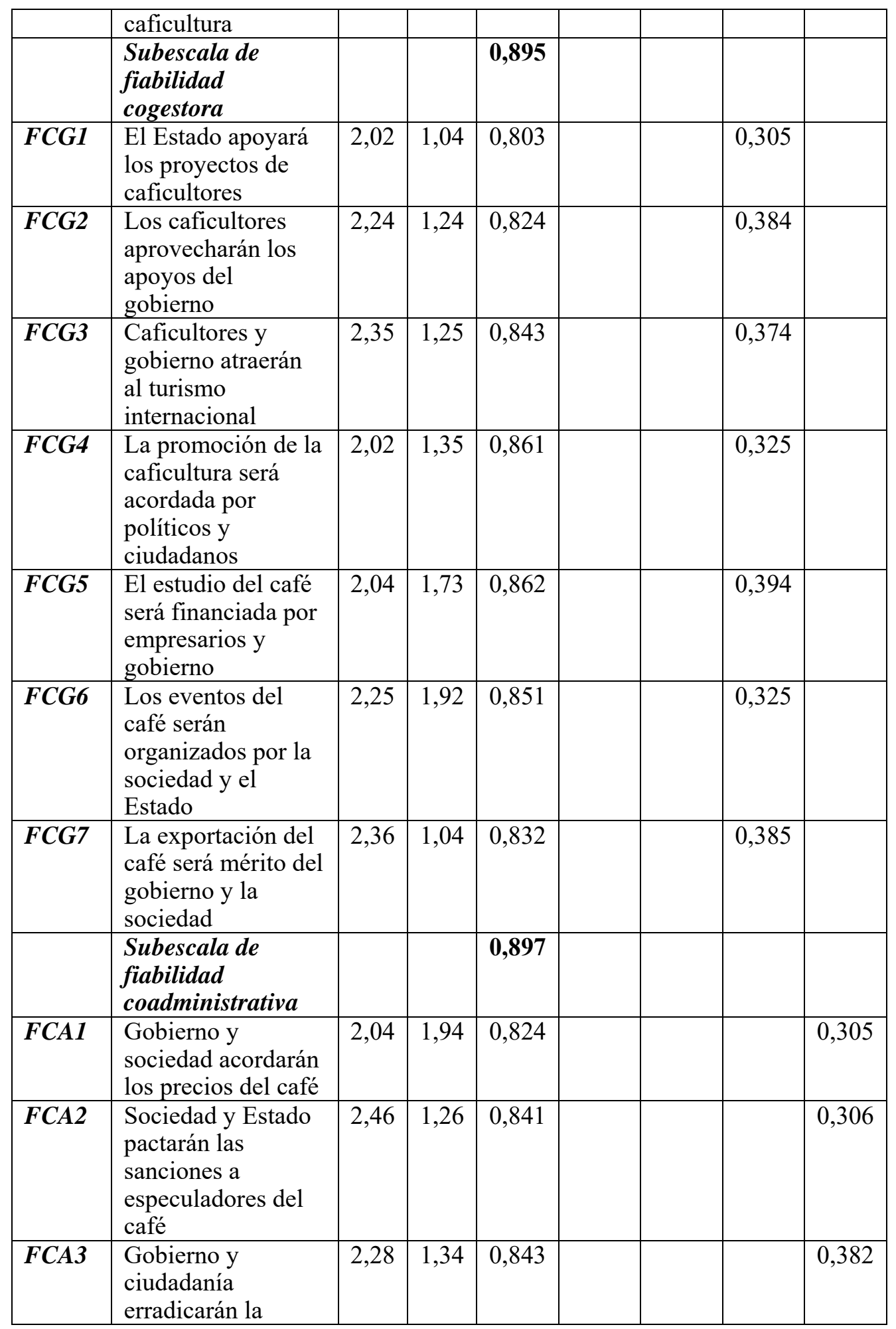




\begin{tabular}{|l|l|l|l|l|l|l|l|l|}
\hline & $\begin{array}{l}\text { competencia } \\
\text { desleal }\end{array}$ & & & & & & & \\
\hline FCA4 & $\begin{array}{l}\text { Ciudadanía y } \\
\text { Estado apoyarán al } \\
\text { café orgánico local }\end{array}$ & 2,39 & 1,82 & 0,871 & & & & 0,375 \\
\hline FCA5 & $\begin{array}{l}\text { Sociedad y } \\
\text { Gobierno vigilarán } \\
\text { la calidad del café } \\
\text { orgánico }\end{array}$ & 2,05 & 1,04 & 0,832 & & & & 0,357 \\
\hline FCA6 & $\begin{array}{l}\text { Autoridades y } \\
\text { ciudadanos } \\
\text { respetarán la } \\
\text { importación de café }\end{array}$ & 2,06 & 1,28 & 0,861 & & & & 0,348 \\
\hline FCA7 & $\begin{array}{l}\text { Gobierno y } \\
\text { sociedad acordarán } \\
\text { reducciones al } \\
\text { precio del café }\end{array}$ & 2,23 & 1,13 & 0,843 & & & & 0,386 \\
\hline
\end{tabular}

Método de extracción: Ejes principales, rotación promax. Esfericidad y adecuación $[\chi 2=234,25(234 \mathrm{gl}) \mathrm{p}=0,000: \mathrm{KMO}=0,713] . \mathrm{M}=$ Media, $\mathrm{DE}=$ Desviación estándar, Alfa valores de consistencia interna quintando la correlación del ítem. F1 $=$ Fiabilidad Gestora (44\% de la varianza total explicada), F2 = Fiabilidad Administrativa (22\% de la varianza total explicada), F3 = Fiabilidad Cogestora ( $16 \%$ de la varianza total explicada), F4 = Fiabilidad Coadministrativa ( $11 \%$ de la varianza total explicada). Todos los ítems tienen opciones de respuesta que van desde $0=$ nada probable hasta $4=$ muy probable.

Fuente: Elaborada con los datos del estudio

El primer factor de fiabilidad gestora explicó el mayor porcentaje de varianza total (44\%), la fiabilidad coadministrativa explicó el menor porcentaje de varianza $(11 \%)$. Es decir que las dimensiones de la fiabilidad parecen concentrarse en la confianza de la sociedad civil para con sus autoridades más que en la corresponsabilidad. 
Tabla 2. Covarianza entre los factores

\begin{tabular}{|l|c|c|c|c|}
\hline \multicolumn{1}{|c|}{ Factor } & FG & FA & FCG & FCA \\
\hline Fiabilidad gestora (FG) & 1,930 & & & \\
\hline Fiabilidad administrativa (FA) & 0,293 & 1,832 & & \\
\hline Fiabilidad cogestora (FCG) & 0,314 & 0,173 & 1,043 & \\
\hline Fiabilidad coadministrativa (FCA) & 0,274 & 0,214 & 0,184 & 1,924 \\
\hline
\end{tabular}

Fuente: Elaborada con los datos del estudio

Respecto a las relaciones posibles entre los factores, la tabla 2 muestra valores espurios que evidencian una estructura común con respecto al constructo de la fiabilidad general. Por último, los valores de ajuste y residual $[\chi 2=134,24(24 \mathrm{gl}) \mathrm{p}$ $=0,003 ; \mathrm{GFI}=0,990 ; \mathrm{CFI}=0,975 ; \mathrm{RMSEA}=0,005]$ sugieren la aceptación de la hipótesis nula relativa al ajuste de las relaciones teóricas entre el constructo general de la fiabilidad con respecto a los cuatro factores establecidos de fiabilidad gestora, administrativa, cogestora y coadministrativa.

\section{Discusión}

El aporte del presente estudio al estado del conocimiento radica en el establecimiento de la confiabilidad y la validez de la Escala de Fiabilidad Sociopolítica. En virtud de que la selección de la muestra no fue probabilística, los resultados sólo atañen a dichos sujetos.

La Escala de Fiabilidad Sociopolítica mide cuatro dimensiones relativas a la gestión, administración, cogestión y coadministración de los recursos y los servicios de financiamiento con respecto a la caficultura como estrategia de desarrollo local, pero en un sentido organizacional, los climas de relaciones, apoyos y tareas no correlacionan con los climas de emprendimiento e innovación, o bien, con los climas de metas.

Es decir que la localidad puede desarrollar relaciones de confianza que se traducen en apoyos y tareas, pero ello no garantiza la competitividad del café orgánico en el mercado internacional. Por consiguiente, es menester profundizar es las correlaciones entre los climas de relaciones, apoyos y tareas con respecto al emprendimiento, la innovación y la efectividad social.

Esto es así porque las redes de conocimiento evolucionan de relaciones de confianza y cooperación a estrategias emprendedoras, innovadoras y efectivas para el Desarrollo Local. Por consiguiente, un estudio correlacional entre la fiabilidad, el emprendimiento, la innovación y la competitividad permitirán observar un proceso de desarrollo local que sería incentivado por la gestión, la administración, la cogestión y la coadministración.

Respecto a la caficultura, como elemento de desarrollo local en cuanto a la calidad de la producción, la acreditación, la certificación y el consumo en el mercado internacional, la Escala de Fiabilidad Sociopolítica permite observar el 
inicio de un proceso de confianza indispensable para el emprendimiento y la innovación social.

En relación con la teoría del capital social el presente trabajo advierte que la fiabilidad sociopolítica, puede ser una divisa principal de municipio caficultor pero la solidaridad y la cooperación en materia de turismo y caficultura no determinarían nuevas identidades y propuestas de corresponsabilidad entre los actores políticos y sociales.

Con respecto al desarrollo humano, la identidad solidaria y colaborativa al no estar vinculada a una identidad emprendedora, innovadora y competitiva inhibiría el establecimiento de consensos y corresponsabilidades entre gobernantes y gobernados.

En el caso de la gobernanza corresponsable, la muestra encuestada muestra que a partir del clima de relaciones, empatía, confianza y apoyo podría generarse una fiabilidad sociopolítica, pero estaría acotada por los límites que supone el establecimiento de redes de conocimiento para el emprendimiento, la innovación y la competitividad.

La sinergia entre gobernantes y gobernados no garantizaría la edificación de una identidad solidaria y corresponsable, emprendedora y cooperativa, innovadora y competitiva como indicativos de capital social, desarrollo humano y gobernanza.

Sin embargo, la fiabilidad sociopolítica es una etapa inicial de la gobernanza corresponsable. El tránsito de la fiabilidad a la gobernanza supone etapas intermedias de gestión, administración, autogestión y autoadministración antes de observar la cogestión y la coadministración.

El estudio de Carreón y García (2014) muestra que la desconfianza es una barrera comprobada de la gobernanza, el desarrollo humano y el capital social, pero la fiabilidad no sólo orienta tales objetivos, tareas y metas sino, además propia el emprendimiento y la innovación cuando se trata de la unión comunitaria ante una crisis ambiental, económica, política o social como la inseguridad, la delincuencia y la violencia (Carreón et al., 2014)

Sin embargo, García et al., (2015) ha demostrado que ante una crisis ambiental, económica, política y social como los conflictos por la cogestión y la coadministración de los recursos y los servicios hídricos la fiabilidad sociopolítica se reduce a su mínima expresión y emerge un clima de desconfianza entre autoridades y caficultores.

En el presente estudio se ha puesto de manifiesto que, en una situación electoral futura, la fiabilidad sociopolítica se intensifica, pero una vez celebrados los comicios es probable que el efecto de la propaganda electoral se disipe y emerja un clima de desconfianza entre gobernados con respecto a sus gobernantes.

Carreón (2016) sugiere que la contienda electoral e incluso posterior a los comicios, la fiabilidad sociopolítica permanece, aunque se reactiva e incrementa ante elecciones posteriores a crisis ambientales y económicas más que políticas o sociales. Es decir que la fiabilidad sociopolítica no sólo se circunscribe a la gestión, administración, autogestión, autoadministración, cogestión y coadministración sino, además estaría indicada por otras formas de relación entre los actores políticos y civiles.

Carreón et al., (2014) asegura que la fiabilidad sociopolítica adquiere un alto contenido emocional más en comicios locales que federales. Ello sugiere que el 
estudio de la fiabilidad sociopolítica podría explicarse por la teoría del establecimiento de agenda, la teoría del cultivo mediático, la teoría de la propaganda, la teoría de las representaciones y la teoría de las actitudes.

La teoría del establecimiento de agenda explicaría la formación de la fiabilidad sociopolítica como un fenómeno electoral en el que los candidatos generan temas vinculados a la economía local con la finalidad de captar simpatizantes, adherentes y votantes.

La teoría del cultivo mediático explicaría el proceso mediante el cual los temas establecidos en la agenda son sistemáticamente utilizados en la difusión intensiva de mensajes a favor de candidatos que velen por los intereses de posibles mayorías votantes dedicadas a una actividad económica en particular.

La teoría de la propaganda explicaría la influencia que el Estado ejerce sobre sus ciudadanos ante una crisis en la que se presentaría como única opción de vigilancia y control de intereses comunes. Es el caso de la rectoría del Estado como propaganda de seguridad e identidad, así como de reproducción de las diferencias entre los actores políticos y sociales ante una crisis.

La teoría de las representaciones sociales explicaría el impacto del establecimiento de la agenda, el cultivo de una propaganda centrada en la rectoría del Estado con respecto a la seguridad agroindustrial, el micro-financiamiento y la asesoría a productos de una actividad económica particular. La formación de un pensamiento social, cristalizado en una opinión del Estado como rector garante de la seguridad explicaría la emergencia de la fiabilidad sociopolítica y su proceso de hibernación posterior a las elecciones.

Por último, la teoría de las actitudes anticiparía escenarios de conflictos y fiabilidad sociopolítica a partir de la distinción entre el efecto de la agenda y la propaganda de la rectoría del Estado en las audiencias emocionales y las audiencias racionales. De acuerdo con la teoría de las actitudes, durante una contienda política las audiencias emocionales procesarían la información de un modo periférico; con la necesidad de obtener información sobre un candidato y sus promesas con respecto a una actividad económica, pero sin profundizar en los detalles del cómo se llevaría a cabo una gestión o cogestión. En contraste, las audiencias más racionales generan una excesiva necesidad de informarse, pero sobre todo de contrastar esa información con sus experiencias para tomar la decisión de apoyar a un candidato.

Se recomienda el estudio de las dimensiones teóricas y conceptuales esgrimidas a fin de poder explicar la emergencia de la fiabilidad y la desconfianza, así como su coexistencia en comicios, o bien, su ausencia posterior a las elecciones.

\section{Conclusión}

La gobernanza del desarrollo local a partir de la fiabilidad sociopolítica entre gobernantes y gobernados con respecto a la caficultura supone fases de confianza, compromiso, emprendimiento, innovación, competitividad y satisfacción que se traducen en gestión, autogestión, cogestión, administración, autoadministración y coadministración de los recursos naturales y los servicios públicos. 
En tal escenario, el estudio de la fiabilidad sociopolítica desde la óptica del capital social, el desarrollo humano y la gobernanza corresponsable supone una construcción de identidades y acuerdos con base en la presunción de que la caficultura es un bien común y por tanto tendrá una repercusión en un futuro común.

Sin embargo, la fiabilidad sociopolítica como indicador de diferencias y acuerdos entre actores políticos y civiles es efímera ya que parece ser un fenómeno que está en el pensamiento de la gente, pero se disipa una vez que se han celebrado las elecciones locales.

Por consiguiente, los marcos teóricos y conceptuales desde los que se han edificado investigaciones empíricas soslayan la importancia de observar a la fiabilidad como un fenómeno mediático, propagandístico, representacional y actitudinal.

Es menester edificar un marco teórico integral que explique el ciclo de la fiabilidad sociopolítica desde su emergencia hasta su disipación, considerando los tiempos electorales, las crisis ambientales, las contiendas políticas y los conflictos sociales.

\section{Referencias bibliográficas}

Araujo, X. (2012). "Una revisión básica sobre conceptos y teorías de gobernabilidad". Geoenseñanza, 9, 203-212

Carreón, J. C., Hernández, J., Bustos, J. M. y García, C. (2017). "Políticas de fomento empresarial y sus efectos sobre las percepciones de riesgo en caficultores de Xilitla, San Luis Potosí, centro de México". Revista Poiésis, 32, 33-51

Carreón, J. (2016). "Desarrollo Humano: Gobernanza, Desarrollo Local y Emprendimiento Social". México: UNAM-ENTS

Carreón, J. y García, C. (2014). "Emociones y desconfianza hacia las autoridades". Viirajes, 16 (1), 163-183

Carreón, J., Hernández, J., Morales, M. L., García, C. y Bustos, J. M. (2014). “Contraste de un modelo de fiabilidad social en función de emociones relativas a la seguridad pública". Psicumex, 4 (2), 44-70

Díaz, C. (2013). "Nueva gestión pública y gobernanza: desafíos en su implementación". International Journal of Conscience, 8, 177-194

Escobar, M. (2012). "La participación ciudadana, análisis a partir de la transición democrática". Revista Internacional de Investigación en Ciencias Sociales, 8, 119-140

García, C., Carreón, J., Hernández, J., Carbajal, C., Quintero, M. L., Sandoval, F. R. y valdés, O. (2016). "Incidencia de las políticas de micro-financiamiento sobre la percepción de emprendimiento caficultor e implicaciones para el Trabajo Social". Ehquidad 6, 11-33

García, C., Aguilar, J. A., Rosas, F. J., Carreón, J. y Hernández, J. (2015). "Diferencias de fiabilidad sociopolítica ante conflictos hídricos entre actores civiles". Invurnus, 10 (2), 3-13 
García, C., Carreón, J., Hernández, J., Aguilar, J. A., Rosas, F. J. y Bustos, J. M. (2015). "Diferencias de fiabilidad ante riesgo, incertidumbre y conflicto entre caficultores de Xilitla, México". Psicoeureka, 12 (1), 73-93

Guillén, A. (2010). "Perspectivas de medio ambiente en Venezuela". Cuadernos UCAB, 10, $29-55$

Innerarity, D. (2012). "La gobernanza global, de la soberanía a la responsabilidad”. Revista Cidob, 100, 11-23

Instituto Nacional de Estadística, Geografía e Informática (2015). “Anuario estadístico y geográfico de San Luis”. México: Inegi

Maisley, N. (2013) “¿Oportunidad u obstáculo? El incipiente derecho a la participación pública en asuntos ambientales globales, a la luz de la Teoría de la Democracia Cosmopolita". Revista de Derecho Ambiental de la Universidad de Palermo, 11, 113 150

Nin, M. (2012). "La gobernanza como clave para comprender el control de la fiebre aftosa la Pampa, Argentina”. Huellas, 16, 36-53

Organización para la Cooperación y el Desarrollo Económico y Organización de la Naciones Unidas para la Alimentación y la Agricultura (2015). "Perspectivas agrícolas 2015-2024”. México: OCDE-FAO

Pérez, G. (2010). "Financiamiento de proyectos urbano-ecológicos mediante intercambio de bonos de carbono". Urbano. 22, 7-21

Piña, E. (2012). "Evaluación prospectiva para la constitución de reservas territoriales para vivienda social años 2012-2025 en la ciudad de San Luis, México". Quivera, 14, 20-46

Rodríguez, P. (2010). “Gobernanza multinivel y política regional europea”. Revista de Estudios Regionales, 88, 199-222

Sandoval, F. R., Carreón, J., García, C., Quintero, M. L. y Bustos, J. M. (2017). "Modelo de los determinantes de la percepción de resiliencia a partir del riesgo y estrés percibidos en relación con la gobernanza de la protección civil”. Invurnus, 12 (1), 30-35

Santamaría, R. (2012). "La acreditación de una necesidad de vivienda como requisito para la transformación del suelo rural". Redur, 10, 193-206 